\title{
Sessões colaborativas na formação inicial e em serviço de professores de inglês
}

\author{
Maria Helena Vieira-Abrahão \\ Unesp - São José do Rio Preto \\ mhabrahao@gmail.com
}

\section{Resumo}

Apresentam-se, neste artigo, alguns resultados da análise de sessões colaborativas desenvolvidas como parte de um projeto de pesquisa-ação colaborativa (BURNS, 1999) com professores de inglês, que buscou compreender como essas sessões se construíram, ou seja, que tipos de ações foram desenvolvidas em seu interior e em que medida estas se constituíram como um espaço propício para a formação docente. $O$ estudo foi fundamentado por uma perspectiva sociocultural. Os dados foram analisados qualitativamente (DORNYEI,2007)echegou-se às seguintes ações mais recorrentes, que serão discutidas ao longo deste artigo:introdução de conceito científico;menção a conceitos cotidianos pelas professoras e demais participantes;relatos e trocas de experiências pelas participantes;mediação pelas formadoras e pelas participantes (professoras e alunas);manifestação de concordância e empatia;digressão na discussão e retomada do foco;planejamento de observações, gravações e visionamento de aulas; apresentação de propostas de atividades práticas pelas graduandas; e sessão de visionamento de aula e discussão. As sessões revelaram-se um espaçofavorável para a formação e o desenvolvimento profissionais.

Palavras-chave: Sessão colaborativa.Formação de professores. Teoria sociocultural.

\begin{abstract}
This article aims at bringing results from the analysis of collaborative sessions, which integrated an action-research project (BURNS, 1999) with teachers of English, that tried to understand how these sessions were constructed, or better explaining, what kind of actions were developed in their interior and in what measure theycan be seen as a promising space for teacher education.The study was based on a sociocultural perspective.Data were
\end{abstract}


Sessões colaborativas na formação inicial...

analyzed qualitatively (DORNYEI, 2007) and have pointed to the following most recurrent actions, which will be discussed in this article: scientific concepts introduction; mention of everyday concepts; reports and exchanges of experience;mediation by the participants; agreement and empathy manifestation; digression from the discussion topic; planning for observation; recording and viewing sessions; presentation of practical activities by the undergraduates and viewing sessions and discussion. The sessions have showed to be a favorable space for teacher education and development.

Keywords: Collaborative session.Teacher education.Sociocultural theory.

\section{Introdução}

Tomando por arcabouço teórico uma perspectiva sociocultural (VYGOTSKY, 1978; 1986; WERTSCH, 1985; JOHNSON, 2009; JOHNSON;GOLOMBEK, 2011), objetiva-se, neste artigo, apresentar resultados da análise de sessões colaborativas envolvendo professoras de inglês em formação inicial e continuada, mestrandas da área de Linguística Aplicada e formadoras, em que se buscou compreender como estas se constituem, ou seja, que tipos de ações foram desenvolvidos em seu interior e em que medida se revelaram um espaço propício para a formação docente.

Essas sessões integraram um projeto longitudinal de pesquisaação colaborativa (BURNS, 1999) que visava àco-construção da prática de ensino de inglês em uma única escola pública estadual e envolveu as duas professoras efetivas, responsáveis pelo ensino da língua inglesa na escola.

As ações do projeto abarcaram o acompanhamento das aulas das professoras pelas estagiárias e pelas mestrandas integrantes do estudo, gravações em áudio e vídeo das aulas, aplicação de questionários para o levantamento das crenças e das expectativas dos alunos e das professoras, entrevistas e sessões colaborativas mensais (com oito horas de duração).

Nestas, buscava-se refletir colaborativamente sobre os sucessos e os insucessos experienciados nas aulas e discutir possíveis encaminhamentos com base nos conhecimentos (conceitos) cotidianos e científicos introduzidos. Como coordenadora do projeto, identificada neste artigo como $\mathrm{C} 1$, ao final das reuniões sempre me questionava se 
nossos objetivos estavam ou não sendo atingidos, se estávamos conseguindo oportunizar a discussão dos dilemas encontrados nas salas de aulae se estávamos promovendo a co-construção de novos conceitos e de novas práticas de ensino de inglês. Questionava-me também se o espaço que havíamos criado estava sendo propício para a formação e o desenvolvimento dos envolvidos, o que era esperado ao desenharmos o projeto. Foram essas inquietações que me levaram a analisar as sessões colaborativas e a buscar compreender sua construção. Entendo que tal compreensão, embora muito particular e contextualizada, possa iluminar meus trabalhos futuros e a reflexão de outros formadores que buscam desenvolver pesquisa-ação colaborativa.

$\mathrm{O}$ artigo desenvolve-se em quatro seções, além desta introdução. Inicia-se com uma breve fundamentação teórica, que busca definir os conceitos da teoria sociocultural a serem empregados para a análise dos dados; apresenta a metodologia utilizada para a coleta e a análise dos dados; a descrição e a análise de alguns resultados da pesquisa e algumas considerações finais.

\section{Fundamentação teórica}

Para o desenvolvimento do projeto e da investigação, tomou-se como fundamentação teóricauma perspectiva sociocultural na formação de professores, conforme apresentada por Johnson (2009) e Johnson e Golombek (2011).

Uma perspectiva sociocultural na formação de professores de línguas reconhece que a formação de professores não é somente um processo de aculturação a práticas sociais de ensinar e aprender existentes, mas se constitui também em um processo dinâmico de reconstrução e transformação dessas práticas de acordo com as necessidades individuais e dos contextos de ensino particulares. Como uma teoria da mente, a teoria sociocultural "tem o potencial para explicar as origens, os processos, a natureza e as consequências do desenvolvimento profissional docente em todas as fases da carreira e 
Sessões colaborativas na formação inicial...

em todos os contextos em que vivem, aprendem e trabalham"(JOHNSON; GOLOMBEK, 2011, p.1). ${ }^{1}$

Para a compreensão dessa perspectiva, faz-se necessário retomar alguns conceitos vygotskyanos que a fundamentam, tais como conceitos cotidianos e científicos, zona de desenvolvimento proximal, mediação, verbalização e internalização.

Os conceitos cotidianosestão intimamente ligados a atividades concretas em contextos sociais. Podem ser retratados como atividade empírica, como conhecimento experiencial, que podem abarcar, no caso da formação de professores, conceitos equivocados ou não, adquiridos ao longo de suas experiências de vida como alunos e professores. Os conceitos científicos, por sua vez,resultam de investigações científicas em qualquer domínio.

De acordo com Friedrich (2012), o fato de os conceitos cotidianos se formarem na experiência, ou seja, em uma relação direta com o mundo, pode indicar a presença de um baixo nível de abstração. Os conceitos científicos, porsua vez, são generalizações de segunda ordem que sempre se realizam por intermédio de um outro conceito. Segundo a autora(2012, p. 100):

Vygostsky mostra que um conceito científico tem uma relaçãotanto com objetos do mundo quanto com outros conceitos. Isso significa duas coisas: 1) os conceitos científicos sempre se apoiam nos conceitos cotidianos, não podendo existir sem eles e 2) um conceito científico existe sempre no interior de um sistema de conceitos.

Isso significa que a construção de conceitos científicos não anula os conceitos cotidianos, mas se apoia neles e os transforma. $\mathrm{O}$ fato de os conceitos científicos não se caracterizarem como"um novo modo de generalização dos objetos do mundo, mas de apresentar um trabalho sobre generalizações já existentes" revela-se um sinal precioso para poder determinar os procedimentos que, de acordo com

\footnotetext{
1 "Has the potential to explicate the origins, mechanisms, nature, and consequences of teacher professional development at all phases of teachers'careers and in all contexts they live, learn and work."
} 
Vygotsky, deveriam ser privilegiados na educação formal (FRIEDRICH, 2012, p. 101).

O desenvolvimento de professores de línguas torna-se um processo de construção, tendo por alicerce os conhecimentos cotidianos sobre linguagem, ensinar e aprender línguas(JOHNSON, 2009)apresentados pelos professores nos cursos de formação docente, seja inicial ou em serviço. Quando compreendidos dentro e por meio dos conceitos cotidianos, os conceitos científicos podem permitir a superação das limitações das experiências cotidianas e a vivência de uma nova experiência em situações e contextos diversos. É justamente na relação dialética, na contradição entre os dois tipos de conceitos, que se origina a zona de desenvolvimento proximal do aprendiz, no caso, do professor em formação.

Zona de Desenvolvimento Proximal (ZDP) é definida por Vygotsky (1978, p. 86) como

[a] distância entre o nível de desenvolvimento real, determinado pela resolução de problemas de forma independente, e o nível potencial de desenvolvimento, determinado pela solução de problemas sob a orientação de um adulto ou em colaboração com pares mais competentes.

Assim,pode ser vista como uma arena de potencialidades, um espaço no qual se pode ver o que o aprendiz consegue realizar com assistência. Em termos práticos, o grande desafio para os formadores é reconhecer os limites desse espaço metafórico e ser estratégico no oferecimento da assistência(LANTOLF;THORNE, 2006), a qual é denominada mediação dentro da teoria sociocultural.Os mesmos autores a definem como

Processo por meio do qual os seres humanos se utilizam de artefatos culturalmente construídos, de conceitos e de atividades para regular (ganhar controle voluntário $e$ transformar) o mundo material ou seu próprio mundo e suas atividades sociais e mentais reciprocamente (LANTOLF; THORNE, 2006, p.79). ${ }^{2}$

2 "Process through which humans deploy culturally constructed artifacts, concepts, and activities to regulate (i.e. gain voluntary control over and 
Sessões colaborativas na formação inicial...

Para Johnson (2009), a assistência,entendida como mediação estratégica, mais comumente referida como andaime, é definida na teoria sociocultural como "uma ferramenta psicológica que reduz a carga cognitiva requerida para o desempenho de uma dada tarefa"(p.22). ${ }^{3}$ Salienta a autora, no entanto, que tal mediação deve ter por meta o desenvolvimento cognitivo para não se transformar em desempenho assistido, e tem de ser "contingente ao que o aprendiz pode desenvolver com a assistência cognitiva que é oferecida e retirada em momentos apropriados "'(p.23). ${ }^{4}$

No caso da formação do professor, é por meio do processo de verbalização sobre suas experiências docentes que o formador consegue perceber o momento estratégico em que amediação deveocorrer, de maneira a impulsioná-lo na construção de novos conceitos e auxiliá-lo no desempenho de tarefas que ele ainda não consegue desenvolver sozinho.

É importante salientar que, de acordo com a teoria sociocultural, a construção de conceitos não acontece por meio da absorção direta daquilo que é ensinado, ou seja, não ocorre por meio dapura transmissão de conhecimentos. A construção de conceitos se dá por meio de um processo de transformação e de internalização, esta última evidenciada quando os conceitos são aplicados em outras situações.Johnson (2009) define internalização como um processo por meio do qual a atividade de um indivíduo é inicialmente mediada por outrem ou por artefatos culturais, porém, mais tarde, vem aser controlada por ele próprio, à medida que se apropria e reconstrói recursos para regular sua própria atividade. Vygotsky via a internalização como "um processo envolvido na transformação de fenômenos sociais em fenômenos psicológicos"(WERTSCH, 1985, p. 63).

transform) the material world or their own and each others'social and mental activity."

3 “ [...] as a psychological tool, one that reduces the cognitive load required to perform a particular task."

4 " [...] contingent on what a learner can do with cognite assistance that is both given and withdrawn at the appropriate points." 


\section{Procedimentos metodológicos}

Como já mencionado anteriormente, a investigação, cujos resultados apresento neste artigo, faz parte de um projeto de pesquisaação colaborativo. Nossa opção por essa natureza de projeto deu-se por acreditarmos, assim como Burns (1999, p. 13), que

[os] processos de pesquisa-ação colaborativa fortalecem as oportunidades de que os resultados de pesquisa sobre a prática possam contribuir com os sistemas educacionais de uma maneira mais crítica e substancial. Têm a vantagem de encorajar os professores a compartilharem problemas comuns e trabalharem cooperativamente como uma comunidade de pesquisa, para examinarem seus pressupostos, valores e crenças dentro das culturas sóciopoliticas da instituição nas quais trabalham. ${ }^{5}$

Para a geração dos dadosforam consideradas as transcrições completas de seis das sessões colaborativas realizadas, escolhidas aleatoriamente. Entendemos por sessões colaborativas no projeto desenvolvido reuniões de todos os participantes para a discussão dequestões relativas ao processo de ensino e aprendizagem de inglês na escola pública, em que se busca valorizar as experiências de cada um dos participantes e uma relação simétrica ou menos assimétrica entre todos os envolvidos. Essas sessões eram realizadas uma vez por mês na universidade, com oito horas de duração, e reuniam os integrantes do projeto colaborativo: $\mathrm{C} 1$ e $\mathrm{C} 2$, coordenadora e subcoordenadora do projeto, ambas linguistas aplicadas e formadoras de professores de língua estrangeira; F e H, professoras de uma mesma escola de ensino fundamental da rede estadual de ensino - a primeira com cerca de dez anos de experiência e a segunda já aposentada e ocupando o segundo cargo efetivo; L e M, mestrandas do PPG em

5 "Collaborative action research processes strengthen the opportunities for the results of research on practice to be fed back into educational systems in a more substancial and critical way. They have the advantage of encouraging teacher to share common problems and to work cooperatively as a research community to examine their existing assumptions, values and beliefs within the sociopolitical cultures of institutions in which they work." 
Sessões colaborativas na formação inicial...

Estudos Linguísticos na área de Linguística Aplicada; e V e E, alunas do curso de Letras, todasda universidade pública onde se desenvolveu o projeto.

As oito horas mensais, concentradas em um mesmo dia, coincidiam com a liberação das professoras da rede pública pela Diretoria de Ensino,tendo sido a única possibilidade para a realização das sessões. Paralelamente, ao longo do mês, como já afirmado anteriormente, as aulas das professoras eram acompanhadas pelas alunas da graduação e pelas mestrandas participantes do projeto, que a observavam, realizavam gravações em áudio e vídeo e aplicavam questionários para os alunos.Os resultados eram discutidos nas sessões juntamente com outras questões práticas e teóricas. Era também função das mestrandas e das graduandas auxiliaras professoras na seleção e na preparação de material complementar ao livro didático adotado na escola, de acordo com as necessidades registradas pelos alunos observados e pelas próprias professoras.

As transcrições selecionadas foram analisadas de uma perspectiva qualitativa por meio da análise de conteúdo (DORNYEI, 2007). Por meio de leituras cuidadosas, os temas que as compuseram foram levantados, agrupados e categorizados. Os dados evidenciaram as seguintes categorias:1.Introdução de conceito científico; 2.Menção a conceitos cotidianos pelas professoras e demais participantes; 3.Relatos e trocas de experiências pelas participantes; 4. Mediação pelas formadoras; 5. Mediação pelas participantes (professoras e alunas); 6.Manifestação de concordância e empatia pelas formadoras; 7.Desvio do foco da discussão pelas participantes e retomada do foco; 8. Planejamento de observações, gravações e visionamento de aulas; 9. Apresentação de propostas de atividades práticas pelas graduandas; 10 . Sessão de visionamento de aula e discussão. Embora todas as categorias assinaladas se tenham feito presentes nas sessões, optamos por abordar mais detalhadamente somente as sete primeiras, considerando a extensão deste artigo. 


\section{Alguns resultados}

Nossas reuniões tinham por meta principal promover a reflexão de todos os envolvidos sobre o processo de ensino e aprendizagem de inglês na escola pública, e, para tal, conceitos científicos eram introduzidos nas sessões. Às vezes isso era feito de forma direta, por meio da leitura de um texto científico ou projeção de uma conferência gravada em vídeo, às vezes era feito de forma indireta, apresentado por uma das mestrandas em forma de síntese ou introduzido nas discussões por uma das formadoras. A introdução de conceitos científicos não obedeciaa uma agenda previamente estabelecida, mas era determinada pelas necessidades dos professores em formação ao longo do processo.

Havia também a preocupação em sempre buscar levantar os conceitos sobre as questões trazidos pelos participantes, fossem cotidianos ou científicos, antes da introdução de novos conceitos, por concordarmos com Vygotsky, que a construção de novos conceitos se dá na relação dialética entre os conceitos já construídos e os novos conceitos introduzidos. Na promoção de oportunidades de construção de novos conceitos, além da mediação oportunizada pelos textos científicos, vídeos de conferências, sínteses e introdução de conhecimentos científicos informalmente ao longo das discussões, buscou-se também oferecer mediação dialógica em momentos estratégicos, como assistência cognitiva para a reflexão e a análise das questões discutidas e para o desenvolvimento de tarefas pelos participantes. Tal mediação era tanto oferecida pelas formadoras como pelas outras participantes do grupo colaborativo, incluindo as duas professoras da rede pública. A seguir, trazemos um excerto que evidencia o oferecimento do conceito científico por meio da leitura de um texto sobre pesquisa-ação colaborativa extraído de Burns (1999), que visava a instrumentalizar os participantes para o desenvolvimento do projeto.

\section{Excerto 1}

1C1- se vocês quiserem olhar esse texto depois de 2pesquisa açãocolaborativa, pra vocês entenderem 3 o que que a gente... talvez a L...ela vai falar um 
4pouquinho do texto e depois se vocês quiserem ler 5 [nesse momento foi entregue uma cópia do texto 6de Burns (1999) para cada uma das professoras e 7demais integrantes do grupo] é bastante 8interessante... [dirigindo-se para L] depois a 9gente... a gente depois. Então a $L$ vai falar um 10pouquinho sobre a pesquisa ação colaborativa 11 pra gente...uma síntese, né, desse texto. É muito 12interessante porque traz um relato dos 13professores...uma professora de matemática $14 \mathrm{~L}$ eu... trouxe um recorte desse texto

$15 \mathrm{C1}$ as partes mais importantes, né?

16L isso é...a parte em que a professora de 17matemática tá contando como tá sendo essa 18experiência .... de pesquisar...de identificar alguns 19 momentos difíceis ... como ela olha pra esses 20momentos.. [leitura de texto]

No excerto anterior, observa-se que o texto que visa a introduzir o conceito científico pesquisa-ação colaborativa foi distribuído para que as participantes pudessem lê-lo posteriormente, caso quisessem. Na sessão, L, uma das mestrandas selecionou parte do texto para leitura conjunta do grupo e buscou facilitar a introdução do conceito científico, sintetizando o que o texto ia apresentar, uma vez que o texto era escrito na língua inglesa e o conceito era novo para algumas das participantes (linhas 16,17,18,19 e 20).

Observa-se como, ao longo da leitura, as participantes se manifestam, trazem o conteúdo do texto- que descrevia a interação de sala de aula de uma das participantes de uma pesquisa-ação colaborativa desenvolvida na Austrália - para sua própria realidade e introduzem sua perspectiva sobre o assunto em questão, fazendo aflorar sua experiência prática e conceitos cotidianos construídos com base nela, conforme pode ser verificado no recorte apresentado a seguir: 


\section{Excerto 2}

$1 \mathbf{L}$ aí é interessante...ela propôs...depois que mapeou...fez 2uma tentativa, entendeu que não era a melhor tentativa...ela 3 caracteriza como mais destrutiva que construtiva, e aí então 4ela vai propor uma outra para reiniciar o ciclo.

$5 \mathrm{C1}$ os alunos não aceitaram muito...os mais fracos se 6sentiram inferiorizados...

7L interessante, né... como a $\mathrm{H}$ já disse, bem próximo 8da(nossa) realidade: eles começaram a chegar tarde, não 9trazerem caneta...

Vozes sobrepostas

10 F é já se sentem discriminados....é uma prática, por 11 exemplo, de fazer atividades em duplas... O que tem 12dificuldade com o que tem maior facilidade?

$13 \mathbf{H}$ aí ela vai ter que determinar...

$14 \mathbf{F}$ mas...é assim os alunos...eles mesmos sabem...quem 15sabe e quem não sabe...inclusive eles já sabem quem 16 escolher...

$17 \mathbf{H}$ é...mas geralmente o mais fraco procura o mais forte 18 mas o mais forte às vezes não procura o mais fraco, não 19 é? É...ele quer de igual para igual...

$20 \mathbf{F}$ adolescente sim...eu falo porque eu dou aula no 21 supletivo...e eu falo para eles: hoje nós vamos fazer tal 22coisa e gostaria que fizessem as atividades em 23duplas...assim...quem tiver maior dificuldade para estar 24 fazendo eu gostaria que sentasse com algum colega que 25poderia estar te ajudando, que entende melhor. Eu falo 26dessa forma. E eu percebo que a maioria senta, porque os 27 colegas ajudam...

Logo no início do excerto 2 pode-se observar a participação de C1 e de L buscando facilitar a compreensão do conceito científico pesquisa-ação colaborativa (linhas 1 a 6). Emseguida, às linhas 7,8 e 9, $\mathrm{L}$ faz relação do que é tratado no texto com a nossa realidade, o que abre espaço para que $\mathrm{F}$ e $\mathrm{H}$, ambas professoras da escola estadual, comecem a trazer suas concepções sobre o pareamento dos alunos, para que uns possam mediar o outro na resolução de problemas (linhas 10 a 27). Essas concepções são construídas com base em observações diretas do contexto de ensino e parecem trazer consigo um baixo grau de abstração, o que permite classificá-las como conceitos cotidianos. A 
retomada desses conceitos cotidianos, colocados dialeticamente com o conceito científico introduzido, pode possibilitar a construção do novo conceito, que, no caso, seria o conceito de mediação, que se faz presente no ensino colaborativo descrito no texto sobre pesquisa-ação que estava sendo apresentado. É interessante observar que, às linhas 17, 18 e 19 , H medeia a construção da concepção de F sobre a questão por meio da pergunta e comentário: é...mas geralmente o mais fraco procura o mais forte mas o mais forte às vezes não procura o mais fraco, não é? É...ele quer de igual para igual, o que evidencia que a mediação não é somente realizada pelas formadoras.

$\mathrm{O}$ excerto a seguir, de número três, evidencia uma discussão sobre a crença o aspecto mais importante no aprendizado da língua é a estrutura da língua, levantada por uma das mestrandas tanto do discurso como das ações das professoras da escola pública. Nele, a mestranda L apresenta a crença, assim como o faz com as demais crenças inferidas, e pede que as participantes da sessão naquele dia (C2, F, H, M, V) se posicionem sobre ela (linhas 1 a 3). Tal pedido, expresso na forma de uma pergunta ("como que cada uma de vocês entende isso?"), pode ser visto como parte de uma mediação dialógica, uma vez que propõe uma tarefa, qual seja, posicionar-se sobre a questão proposta, que envolve a verbalização de um conceito possivelmente já internalizado sobre a importância da estrutura na aprendizagem de uma língua estrangeira.

\section{Excerto 3}

1.......Aí o primeiro, então... [leitura do texto] "o aspecto 2mais importante no aprendizado da língua é a estrutura da 3 língua". Como que cada uma de vocês entende isso?

4F Não não é o mais importante

5H é a maioria das pessoas sem estar em uma escola ela 6aprende a língua também. sem ser pelo meio acadêmico, 7 pela vivência.

$8 \mathrm{C} 2$ aprender no uso, só?

9H Não, ah, não, ah aprende a língua [releitura do texto: “o 10aspecto mais importante

11no aprendizado da língua é a estrutura da língua"] Você 12 pode aprender a língua sem estar preocupado com a 13 estrutura dela, vamos dizer assim, aprender, se comunica, 14fala mal e tal mas se comunica 
15L ou até falar bem, mas não saber porque você usou essa 16palavra nessa hora?

$17 \mathrm{H}$ é ...

$18 \mathbf{L}$ e você $\mathrm{C} 2$...o que você acha?

19 C2 não é o mais importante mas é muito (ênfase) importante ainda (risos)

$20 \mathrm{H}$ principalmente para nós professores que a gente bate o 21olho em um texto e já detecta aquele mundo de 22 coisa...'olha aqui está errado, ..."

$23 \mathrm{C} 2$ isso tem sido deixado um pouco de lado então, por 24exemplo, eu entrei para

25aula de italiano para o quarto ano [do curso de letras] e eu 26vejo que os alunos sabem falar sobre a estrutura, e eu 27 achei isso muito grave porque eles vão ser professores.

28 F Eles têm que saber porque eles vão ensinar depois, né? 29C2 Eles gostam de saber

$30 \mathbf{M}$ (vozes sobrepostas) agora, com esse projeto eu vejo 31que EU estou me policiando um pouco. Na sala de aula, 32eu tento fugir um pouco da gramática, mas eu acho que é 33 como a $\mathrm{F}$ falou: eu sempre me pego explicando regras e 34exceções ponho assim na lousa. E deixa eu problematizar 35assim: a gente tem que fugir? não sei... Depois que eu 36 entrei aqui que eu comecei a pensar um pouco mais sobre 37isso...Eu ainda não estou pronta para mudar.

$38 \mathbf{F}$ porque você tem que ter alguma coisa para te amparar 39 [ensino da gramática].

40Porque se você deixa... não é deixar, mas se você dá 41menos importância ela [gramática] vai sumindo com o 42tempo. Você acaba não tendo nada para te amparar. Acho 43tudo tem alguma coisa (trecho incompreensível), acho 44que faz parte.

45L ela tem o mesmo peso dos outros aspectos?

46C2 O que que vocês acham? Essa é uma pergunta muito 47importante ela tem o mesmo peso?

Vozes sobrepostas

$48 \mathrm{H}$ eu acho que depende

$49 \mathrm{~F}$ da situação

50F vamos ver... um aluno que está interessado em aprender 51uma segunda língua...

52 vamos ver... ele quer aprender a falar logo, mas como ele 53vai aprender a falar se ele não souber usar a estrutura? Aí 
Sessões colaborativas na formação inicial...

54entra! Não tem como você separar uma coisa envolve a 55outra. chega um aluno e fala: 'Quero aprender 56conversação'. Você vai deixar ele só falando? Como que 57 você vai ensinar os tempos?

$58 \mathrm{H}$ é...eu não sei ensinar se não for com a estrutura. Então 59se for para eu ensinar, sem mexer com a estrutura, eu não 60 sei porque eu aprendi [com o professor] me mostrando a 61estrutura.

62C2Então...mas você fala sistematizando, mesmo, né?

63Hiiiiisso! Então, eu aprendi assim. Eu não sei... Mas 64então para mim é muito

65difícil me desvencilhar disso. .. . Igual as vezes eles 66querem que você não tem que mencionar nada 67[metalinguagem] para ser comunicatIvo, só para se 68comunicar e tal: eu não consigo! Não é que a gente 69 prioriza, mas é que eu não consigo me desligar! Para 70mim, não é prioridade, mas eu não sei

$71 \mathrm{C2}$ Mas então como você vê isso: primeiro você sente a 72necessidade de sistematizar e depois mostrar o uso? Ou ao 73contrário: primeiro você mostra o uso e depois 74 sistematiza?

$75 \mathrm{H}$ eu acho que o ideal seria igual eu dei um exemplo hoje: 76um aluno....

Esse excerto evidencia a participação do grupo na discussão do tema proposto, a importância da estrutura no ensino de línguas e a presença de mediação quer de uma das formadoras (C2), às linhas 8, 46, 62, 71, 72, 73 e 74) quer damestranda L (linhas 15, 16, 18 e 45). Observa-se que as mediações são realizadas em forma de perguntas, que conduzem à análise do conceito discutido.

Ao responderem à pergunta feita por L logo no início da interação, F e H, ambas professoras da escola pública, negam que a estrutura seja o aspecto mais importante na aprendizagem de uma língua estrangeira (linhas 4, 5, 6 e 7), mas são levadas a pensar melhor sobre o conceito devido à pergunta mediadora de $\mathrm{C} 2$ : aprender no uso, só?. A partir da pergunta, $\mathrm{H}$ reformula seu discurso, trazendo informações sobre a qualidade da aprendizagem (Você pode aprender a língua sem estar preocupado com a estrutura dela, vamos dizer assim, aprende, se comunica, fala mal e tal mas se comunica), e é imediatamente mediada por L, cuja indagação faz todos pensarem 
sobre a questão (ou até falar bem, mas não saber porque você usou essa palavra nessa hora ?), o que é seguido pela afirmação de $\mathrm{H}$.

Mais adiante, a discussão caminha em direção à valorização da estrutura na aprendizagem de uma língua estrangeira (linhas 19 a 44) e é interrompida pela mediação de L (linha 45) e repetida por C2 (linha 62) com o propósito de levar os participantes a sintetizarem o conceito discutido, ao pensarem se a estrutura tem o mesmo peso que os outros aspectos. Com o mesmo propósito ocorre a mediação de $\mathrm{C} 2$, às linhas $71,72,73$ e 74, em que busca oferecer assistência cognitiva para que $\mathrm{F}$ consiga analisar melhor a questão e desempenhar a tarefa a contento, qual seja, posicionar-se sobre o tema proposto, quando pergunta: Mas então como você vê isso: primeiro você sente a necessidade de sistematizar e depois mostrar o uso? Ou ao contrário: primeiro você mostra o uso e depois sistematiza?

No excerto 4, a seguir, novamente evidenciamos momentos de mediação para que a participante, no caso a professora $\mathrm{F}$, possa melhor articular seu posicionamento sobre a promoção de mudanças em sala de aula. Essas mudanças a que se refere dizem respeito a trabalhar de forma mais relaxada, cobrando menos de si própria, o que diz não conseguir e quepode ser atribuído ao fato de ela ser uma profissional muito responsável, e ao uso de tarefas mais motivadoras e interativas na sua prática, muitas das quais foram elaboradas no grupo com o auxílio das mestrandas e das alunas de graduação envolvidas no projeto com base no livro didático adotado por $\mathrm{F}$ e $\mathrm{H}$.

\section{Excerto 4:}

1F: Eu tô assim, a ponto de sabe, chega sábado e se eu não 2preparei as minhas aulas não consegui preparar eu tenho 3que ficar o domingo, eu perco, eu deixo de às vezes sabe; é 4um horror. É. Eu tava até pensando isso, um pouco na 5minha vida prá mudar. Então eu tenho que mudar? Tenho. 6Agora é complicado, eu já te falei, eu dou quarenta e tantas 7aulas, tem um monte de coisas; então eu fico nessa 8preocupação, nessa ansiedade, nessa coisa, tem que dá 9 prova, tem que dá avaliação, tem que dá nota, tem que não 10sei o que; então eu fico doidinha; então é a questão da 11 minha cobrança você entendeu?

12C1: F vamos olhar para o seguinte, por exemplo, 13 cobrança institucional existe? 
14F: Não [vozes sobrepostas]

15C1: Então, quer dizer, cobrança institucional é uma coisa 16que você tem na escola de língua né.

17F: As professoras mais experientes tal, falam que aí não 18pode ser assim, que é exagero, você é novinha coisa e tal, 19 tem que mudar, mas eu não vou mudar, não é questão de 20idade não, é minha natureza.

21C1: Oh, vamos falar, cobrança institucional não existe, 22quer dizer, no contexto onde você trabalha você tem mais 23liberdade.

24F: mas eu tenho também um compromisso a cumprir, 25porque [vozes sobrepostas].

26H: Não, mais eu não acho que você tem que se cobrar por 27isso e às vezes você tá trabalhando até melhor que eu 28 [vozes sobrepostas]. Mais não tem problema isso pra $29 \mathrm{mim}$, eu sempre falei eu sou mais pela, não pela 30quantidade eu sou pela qualidade. Eu acho que você não 31 tem que porque programou aquilo tem que correr com 32aquilo porque [vozes sobrepostas]. Ela tentou se justificar 33 muito pra mim porque eu peguei alunos que eram dela: 34Olha, porque eu nas minhas sextas séries, eu não 35 conseguia apertar; mas eu falei tudo bem, esse começo de 36ano, quer dizer é, pra mim não é

37problema; ela coloca mais problemas, realmente é uma 38 coisa que você precisa trabalhar isso em você e isso te 39desgasta muito.

40C1: Deixa eu te fazer uma pergunta $F$. Eu acho que é uma 41coisa $F$ que parece que em tudo que você faz a questão 42do tempo pra você é crucial, e é algo que de certa forma 43te atrapalha; quer dizer, você gostaria de fazer coisas e 44não faz por causa do tempo. Você gostaria de fazer 45 melhor algumas coisas, você não faz por causa do tempo. 46Então, eu acho que aqui nesse aspecto, eu acho que se a 47 gente fosse focalizar bem essa prática e verificar o que tá 48realmente pegando aí pra você, é a questão do tempo, 49 você reconhece. Eu pergunto, o fato de vocês estarem 50 ambas dentro de um único projeto né, vocês estão em 51constante contato né, isso não é o suficiente pra você?

52F: É suficiente, mas eu sinto que falta, parece que eu não 53 cumpri com tudo que eu tinha que cumprir. Por exemplo, 54passar tarefa, dar tarefa, eu to dando e as correções eu 
to55fazendo assim, igual você; enquanto eu vou olhando o 56que ele fez eu vou pedindo pra ele por as atividades, as 57respostas na lousa, aí a gente discute e mesmo assim eu 58tenho que ta, mesmo assim eu tento isso. Eu to seguindo 59 essas orientações, eu to fazendo, não to deixando de fazer. 60Dei a música, to dando jogos, to fazendo, to tentando 61aplicar pra eu mudar entendeu? Eu to fazendo isso, mais 62eu sinto que falta alguma coisa, que não ta completo, eu 63sinto que parece que eu tinha que trabalhar mais aquilo $64 \mathrm{com}$ eles; eu não sei se eu sinto ou se eu sinto que eles 65 sentem, eu não consigo.

No início do excerto (linhas 1 a 11), deparamos com um desabafo da professora quanto às dificuldades para cumprir bem suas obrigações profissionais e imprimir mudanças em sua prática, que ela diz serem necessárias. Pela maneira como se coloca, a instituição parece ser responsabilizada pela sua falta de tempo em modificar seu trabalho. Com o propósito de levar a professora a avaliar melhor tal problemática, temos a mediação dialógica de $\mathrm{C} 1$, configurada pela pergunta:vamos olhar para o seguinte, por exemplo, cobrança institucional existe? e pelas afirmações: Então, quer dizer, cobrança institucional é uma coisa que você tem na escola de língua néeOh, vamos falar, cobrança institucional não existe, quer dizer, no contexto onde você trabalha você tem mais liberdade. Tal mediação leva a professora a reafirmar o compromisso na escola, compromisso esse não totalmente expresso aqui pela incompreensão da fala no momento da transcrição, mas que se torna compreendido pela fala seguinte de sua colega $\mathrm{H}$. F é responsável pelo ensino de inglês nas quintas e sextas séries, enquanto $H$, pelas sétimas e oitavas na mesma instituição. H busca também mediar a compreensão da problemática por $\mathrm{F}$, trazendo outra visão da situação, mostrando que não se importa se ela cumpriu todo o conteúdo ou não quando recebe seus alunos na sétima série, que o mais importante para ela é a qualidade do que foi ensinado e aprendido (linhas 26 a 39).

Percebendo nas entrelinhas que o maior problema para a realização de mudanças na prática se resume ao tempo, $\mathrm{C} 1$ busca sintetizar o que parece perturbar a professora e, depois disso, lança uma pergunta com o intuito de mediar a compreensão do problema por ela, às linhas 49,50 e 51:Eu pergunto, o fato de vocês estarem ambas 
Sessões colaborativas na formação inicial...

dentro de um único projeto né, vocês estão em constante contato né, isso não é o suficiente pra você? Ao que a professora diz que sim e acaba por justificar sua insatisfação ao imprimir modificações em sua prática, modificações essas acordadas pelo grupo colaborativo. Ela diz tentar implementar mudanças, mas acha sempre que seu trabalho está incompleto, talvez pelo fato de serem atividades interativas que não se apoiam na gramática(linhas 52 a 65 ).

Apesar de a mediação se fazer presente em muitos momentos estratégicos nas sessões colaborativas, oferecendo assistência cognitiva por meio de questionamentos e de problematização para impulsionar a construção de novos conceitos e a resolução de tarefas, perderam-se, em vários momentos das sessões, oportunidades para mediar a análise e a síntese dos assuntos tratados, dando origem à ZDP. Em alguns momentos, ao invés de criar situações de contradição por meio de uma postura dialética que pudesse oportunizar alguma transformação, criou-se um clima de concordância e de empatia, talvez pela dificuldade de se conciliar essa atitude com o clima afetivo de baixa tensão e de relações menos assimétricas que uma pesquisa-ação colaborativa proclama. A seguir, trazemos um desses momentos.

\section{Excerto 5:}

1 F (...) é... lembra que a gente criou... preparou 2algumas...(atividades) pra dar as unidades aquela::

$3 \mathrm{C1}$ (...) isso, foi nossa alternativa

$4 \mathbf{F}$ até trouxe o livro...

$5 \mathrm{C1}$ você quer fazer...vamos fazer o seguinte $\mathrm{F}$ faz uma 6análise, assim...do que você tem, do que você desenvolveu. 7Tenta fazer um relato, por exemplo, da ação

8que você desenvolveu nesse período. Quer dizer, não 9é....eu quero que vocês entendam o seguinte-- não há uma 10cobrança da nossa parte, não é porque... nós fechamos a 11última reunião com algumas propostas que essas 12propostas têm que

13 ser necessariamente aplicadas, entendeu?

$14 \mathbf{H}$ é...às vezes não deu, ainda não deu tempo. A gente tem, 15 no decorrer do mês, os imprevistos que acontecem. Às 16 vezes no dia da sua aula você não tem aula, né? Ou tem 17alguma outra atividade na escola que você não vai 18naquela sala. Então tem percalços, mas é::: 
19 C1 (...) Não::, a gente sabe. Então não se sintam, nesse 20momento, cobradas. Porque nós entendemos 21perfeitamente como as coisas se desenrolam.......

22F Mas é interessante falar...o que funcionou e o que não 23funcionou...

$24 \mathrm{C} 1$ Isso, F. Então vamos ver, por exemplo, a ação. Como 25você descreveria sua ação...Vamos seguir esse roteiro?

$26 \mathbf{F}$ Não, primeiro eu gostaria de falar -- lembra quando a 27 gente discutiu sobre jogos aqui - para aplicar dentro das 28unidades? Na unidade 7 eram comandos, que a gente 29discutiu lá de fazer com eles, aí eu fiz os cartões dos 30 comandos e eu falava, dividia a sala em grupos....

$\mathrm{O}$ excerto de número cinco traz um momento de uma sessão reflexiva cujo foco era analisar o que, do que havia sido construído de forma colaborativa pelo grupo, estava sendo colocado em prática nas aulas de inglês. F descreve o que conseguiu ou não trabalhar em suas aulas, analisando brevemente o que aconteceu quando as atividades foram trabalhadas. $H$ auxilia $F$ a justificar a dificuldade de se desenvolver o trabalho desejado em virtude de interferências nas aulas de inglês (14 a 18). A formadora $\mathrm{C} 1$ acolhe as justificativas e mostrase compreensiva ante os empecilhos encontrados na escola pública, procurando deixar claro que não havia cobrança do grupo (linhas 9 a 13 e 19 a 21). Tal posicionamento de $\mathrm{C} 1$ talvez revele preocupação em manter um clima de baixa tensão no grupo, atenuando uma relação assimétrica na relação formador universitário e professor da rede pública, uma vez que a proposta era de co-construção de conhecimentos dentro de um projeto colaborativo. Porém, neste momento, a questão da falta de tempo para a implementação das atividades poderia ter sido problematizada, uma vez que nas entrelinhas se pode perceber que estas somente tinham lugar depois de o cumprimento da lição do livro didático, ou seja, eram concebidas como atividades suplementares e descartáveis.

Por não haver uma agenda e um planejamento rígidos para o desenvolvimento das sessões colaborativas e pelo próprio espírito do projeto, que buscava certa informalidade nas reuniões, tentando estabelecer um clima agradável e de baixa ansiedade para todos,os dados evidenciaram muitos momentos de digressão do tópico objeto da discussão, como se podeconstatar no excerto a seguir. A apresentação 
Sessões colaborativas na formação inicial...

do conceito científico pesquisa-ação colaborativa por meio do texto de Burns (1999) foi interrompida por F, que deu início a uma longa discussão no grupo sobre formação em pré-serviço e os estágios supervisionados.

\section{Excerto 6}

$1 \mathbf{L}$ é... com experiência que trabalhava no..." Australian2Adult Migrant

3Program" e aí em virtude de mudanças políticas e 4governamentais ela

5pega essa sala que é diferente de tudo que ela já tinha mais 6contato,

7 mas...[o texto] classifica ela como uma professora bastante 8experiente

9F é que eu questionei porque ela fala 'supportteacher' e 10nós lemos essa

11semana no HTPC um texto eu não lembro o nome do 12autor...é um

13português...lá de Portugal...

14C1Nóvoa

15F O Nóvoa. Ela fala que os professores novos, no caso 16inexperientes, quando

17entram, assumem alguma classe que..que a escola tem que 18dar suporte pra ele,

19professor. Não colocar ele nas sala que têm 20problema...sempre dar uma

21classe mais .... porque eles estão entrando, iniciando a 22prática , né? Então não deveria ser assim ... deveria ter 23sempre um professor como suporte para esse novo 24professor, professor novo, né?

$25 \mathrm{C} 1$ mas você sabe que em Portugal existe...

$26 \mathbf{F}$ como se diz.... aqui é utópico isso, né? Pelo contrário, 27 os professores

28novos pegam as piores salas e...são judiados, os coitados 30aprendem

31ali na marra, sozinhos, não tem condições (vozes sobrepostas).....

O excerto 6 retrata uma digressão do tema proposto para a reunião, introdução do conceito científico pesquisa-ação colaborativa, 
desencadeada pelo termo support-teacher utilizado por Burns (op.cit.). $\mathrm{F}$ relacionou o termo a um texto do educador português AntonioNóvoa, que discutira em sua reunião de HTPC (linhas 9 a 13), sobre o qual discorre para o grupo às linhas 15 a 24. Tal digressão, que se inicia pela recuperação de conceitos científicos introduzidos pelo autor português, dá margema considerações dos participantes com base em suas próprias vivências no ensino público e na formação de professores, das linhas 25 em diante.

A digressão do tema central proposto para a reunião prolongase, passando pela discussão da organização dos estágios supervisionados de maneira geral e na universidade, onde o projeto se desenvolveu, até que $\mathrm{C} 1$ propõe o retorno à leitura do texto programada para a sessão, o que pode ser evidenciado no excerto a seguir.

\section{Excerto 7}

1C1 é de coordenador de estágio dentro da escola 2pública..coisa que aqui a gente não tem. Então...esse 3'support teacher' é uma coisa meio difícil vocês por 4exemplo estão tendo 'supportteacher' no processo, mas 5são duas professoras e quantas da rede?...né...Infelizmente 6é assim. Bom, então vamos continuar?

(Leitura do texto)

\section{Algumas considerações}

A análise das sessões colaborativas e os excertos apresentados denotam o envolvimento das participantes nas ações descritas, com especial destaque para as coordenadoras, as professoras da rede pública e a mestranda L. O ensinode inglêsna escola pública é discutido, conceitos experienciais (cotidianos) são trazidos à baila, oportunizando a introdução de conceitos científicos e de mediação. Mesmo oferecendo o conhecimento científico, por meio de leituras, palestras gravadas em vídeo e inserções indiretas nas discussões, e registrando a presença constante de mediação dialógica oferecida estrategicamente para impulsionar por meio da relação dialética a construção de novos conceitos na zona de desenvolvimento proximal, os dados sugeriram 
Sessões colaborativas na formação inicial...

que a construção de novos conceitos é uma tarefa difícil e tortuosa, caracterizada por idas e vindas (SMAGORINSKY; COOK; JOHNSON, 2003). Tal dificuldade pode ser inferida do excerto de número 3 ,em que se discute a importância da estrutura na aprendizagem de línguas, algo que já havia sido muito explorado ao longo das sessões. Desde o início do projeto, ao perceber que as aulas na escola pesquisada eram essencialmente gramaticais e que os alunos se mostravam desmotivados, buscou-se introduzir no grupo conceitos socioculturais de aprendizagem, com ênfase na comunicação, o que ainda não parece ter sido internalizado pelas participantes. Ao final do excerto 3, as participantes C2, F, H e M assumem a grande importância que atribuem à gramática na aprendizagem de uma língua estrangeira.

Também foi observado na análise que muitos foram os momentos nos quais a mediação não ocorreu, embora tivesse sido necessária para promover a análise e a síntese do conceito discutido. Isso talvez se justifique por duas razões: a difícil tarefa de mediar e a preservação de um clima de motivação e de baixa ansiedade no grupo colaborativo. Será que realmente conseguimos ser estratégicos no oferecimento da mediação? Até que ponto conseguimos efetivamente oferecer assistência cognitiva que contribuísse para que o aprendiz pudessedesenvolver-se cognitivamente e desempenhar melhor sua tarefa? Sem dúvida, a questão é complexa. Reafirmando o que dizem Lantolf e Thorne(2006), na prática, reconhecer os limites da ZDP e ser estratégico no oferecimento da mediação é uma tarefa difícil. Em nossas sessões, muitas oportunidades foram ignoradas em função dessa dificuldade.

Quanto ao segundo aspecto, preservação de um clima afetivo propício dentro do grupo, em que se objetivava a co-construção do ensino de inglês na escola pública, embasada nas experiências de cada um e nas teorias da Linguística Aplicada, este muito influenciou as ações do projeto. Em muitos momentos o foco principal das discussões foi desviado, cedendo lugar a longos relatos de experiência, considerações pessoais sobre fatos ocorridos na escola, questões pontuais sobre alunos, pais, coordenação, o que pode ser visto positivamente, pois para buscar a co-construção do ensino de inglês na escola pública em questão precisávamos conhecer bem a realidade escolar. E também o relato das experiências pode evidenciar conceitos 
cotidianos das participantes que poderiam contribuir para construções dos conceitos científicos.

Porém, com o propósito de não interromper os relatos espontâneos e as trocas de experiências pelas participantes, muitos momentos estratégicos de mediação foram perdidos, como exemplifica o excerto 5, e, ao final da sessão, era frequente a sensação de que o objetivo estabelecido para aquela sessão não fora atendido.

Apesar de algumas ações não previstas, como a digressão do foco principal, que ocorreu com frequência,a análise dos dados evidenciou que as sessões colaborativas se mostraram muito propícias para que professores em formação inicial pudessem interagir com professores já experientes, pudessem vivenciar direta e indiretamente a realidade da escola pública, tivessem espaço para participar da discussão de problemas vivenciados por alunos e professores, à luz das experiências de cada um e à luz dos conceitos científicos introduzidos na medida do necessário pelos professores formadores, embora os excertos trazidos neste artigo não evidenciem tal participação. Constituíram-se tambémum espaço promissor para que os professores atuantes no ensino público pudessemretornar à universidade e refletir sobre suas experiências, conflitos e anseios, recebendo a mediação de formadores experientes e dos próprios colegas, além da oportunidade de atualização teórica. Para os alunos mestrandos e doutorandos, além dos conhecimentos construídos por meio das ricas trocas propiciadas pelo grupo, as sessões puderam ser utilizadas também como um fértil cenário de pesquisa e de aprendizagem. Para os formadores, constituíram-se em uma excelente forma de aproximação com o que efetivamente ocorre nas escolas. Resumindo, com base na análise realizada, pode-se afirmar que as sessões dessa natureza, mesmo imprevisíveis, têm o potencial para o desenvolvimento profissional de todos aqueles que dela participam.

Embora o projeto tenha trazido contribuições para cada segmento, a análise das sessões apontou alguns pontos que merecem atenção em futuras experiências: 1. maior cuidado com o equilíbrio entre as falas dos participantes: há o predomínio das falas de $\mathrm{C} 1, \mathrm{~F}, \mathrm{H}$, $\mathrm{L}$, nessa ordem. C2 tem uma participação maior na ausência de C1; V e E mais observam do que falam;2. maior atenção aos momentos estratégicos para realizar mediações e à qualidade destas (as sessões precisam fomentar a reflexão, a análise e, se pertinente, a construção 
Sessões colaborativas na formação inicial...

de novos conceitos, e isso nem sempre aconteceu); 3. cuidar para que o tópico das discussões não seja totalmente desviado, o que prejudica atingir o objetivo proposto para a sessão; e 4.estabelecer objetivos mais precisos para cada reunião, envolvendo todos os participantes.

\section{Referências}

BURNS, Anne. Collaborative action research for english language teachers. Cambridge:Cambridge University Press, 1999.

DORNYEI, Zoltán. Research methods in applied linguistics: quantitative, qualitative and mixed methodologies.Oxford: Oxford University Press, 2007.

FRIEDRICH, Janette. Lev Vigotsky: mediação, aprendizagem e desenvolvimento: uma leitura filosófica e epistemológica. Trad. Anna Rachel Machado e Eliane Gouvêa Lousada. São Paulo: Mercado de Letras, 2012.

JOHNSON, KarenE. Second language teacher education: a sociocultural perspective. New York: Routledge, 2009.

; GOLOMBEK, PaulaR. (Ed.).Research on second language teacher education: a sociocultural perspective on professional development. New York: Routledge, 2011.

LANTOLF, JamesP.; THORNE, StevenL. Sociocultural theory and the genesis of second language development. Oxford: Oxford University Press, 2006.

SMAGORINSKY, Peter.;COOK, Leslie S.; JOHNSON, Tara S. The twisting path of concept development in learning to teach.Teachers College Record, v. 105, n. 8, p. 1399-1436, 2003.

VYGOTSKY, Lev.A. Mind in society. Cambridge, MA: Harvard University Press, 1978. 

. Thought and Language.KOZULIN, Alex.(Ed.). Cambridge, MA: MIT Press, 1986.

WERTSCH, JamesV. Vygostsky and the social formation of mind. CAMBRIDGE, MA: Harvard University Press, 1985.

Submetido em: 06/01/2014 Aceito em: 29/09/2014

Title: Collaborative sessions in initial and in-service education of teachers of English 